To cite this article:

Littlejohns, R., Gouthro, M.B., Dickinson, J.E. 2019. Runners' Engagement and Social Support Practices: Exploring the Uses and Role of Online Activities. Sport in Society,

https://doi.org/10.1080/17430437.2019.1571486

\title{
Runners' Engagement and Social Support Practices: Exploring the Uses and Role of Online Activities
}

\begin{abstract}
Tracking technologies that monitor exercise and health have grown in popularity, while online communities have emerged to encourage healthier lifestyles. Runners display high engagement levels with these technologies, however, studies are inconclusive about the effectiveness of these tools, and half of tracking device owners stop use within three months. This exploratory study analyses the engagement practices of UK based long distance runners with tracking technologies and online communities in order to explore how these provide social support for runners. Data were derived from nine interviews. Findings identify distinct use practices associated with social networking sites, running club online communities and tracking applications. Social support is not as prominent as social comparison, identity formation, motivation and information gathering for runners. The nature of the community, co-present connections between individuals and running experience have implications for engagement and support practices, while emotional attachment to data represents an opportunity for development.
\end{abstract}

\section{Introduction}

The use of tracking technology has become wide spread, ranging from applications that track the number of steps taken, to those that log cafes visited. Recent studies show growth in wearable devices sold (Mintel 2016), download of smartphone tracking applications (Krebs and Duncan 2015) and use of technology to monitor health and fitness (Mintel 2017). Tracking technologies frequently provide community sharing functions and online health and fitness communities are growing and diverse. Communities facilitate social support (Wellman et al. 2001; Oh et al. 2014) and online communities have the potential to benefit health and increase levels of physical activity (Brummett et al. 2001; Reed et al. 2011).

Given concerns about sedentary lifestyles (Public Health England 2016), technological solutions are also emerging in health that monitor activity and symptoms remotely and seek to engage users in more physical activity (Comstock 2013, Deloitte 2015). For instance, researchers have investigated the potential of online communities to encourage physical activity and weight loss (e.g. Ba and Wang 2013; Hwang et al. 2010). However, studies in health and fitness have provided mixed results on the benefits of tracking technology and online communities as interventions for encouraging physical activity and weight loss (e.g. Jakicic et al. 2016; Cavallo et al. 2012; Stragier et al. 2015). Furthermore, 
whilst the uptake of wearable devices is growing, 38\% of owners stop using the device shortly after purchase (Mintel 2016) and a recent study found 54\% of participants stopped using their device within three months (Valencell 2016).

The body of research on fitness communities, tracking applications and wearable devices is small, although growing. The literature is dominated by health related research, with a strong focus on the possible benefits of utilising online communities and tracking technologies to promote, encourage and sustain weight loss and physical activity.

This study leans more towards the leisure domain, an important area of academic activity in the context that relates to active lifestyles (Clough et al. 1989, Goodsell \& Harris 2011). To begin to understand the engagement practices and outcomes of using these technologies, this study focused on runners. Runners exhibit high levels of engagement with online communities and tracking technology. For example, many running specific tracking technologies report having over 16 million users, and the popular 'RunKeeper' reported 22.5 million users in 2013 (Comstock 2013). The aim of this study is to critically analyse runners' engagement with online activities in relation to tracking technologies and online communities in order to explore how these provide social support for runners.

\section{Online Community and Social Support}

Technology has connected more geographically dispersed communities and individuals now have access to their own personal networks (Wellman et al. 2001), regardless of physical place, that provide a space for exchanging support (Chiu et al. 2015; Oh et al. 2014). Community membership has traditionally provided access to resources and social support (Wellman and Wortley 1990) which is important for wellbeing (Cobb 1976; Cassel 1976). It has been associated with creating healthy norms, such as participation in physical activity, as well as providing assistance in carrying out the activity itself (Putnam 1995; Sherwood and Jeffery 2000; Bauman et al. 2012). Online communities extend this support and can help grow networks, creating positive outcomes for participants (Wilcox and Stephen 2013). However, there are other perspectives, for example the social capital derived from online communities can conserve access to resources and be exclusionary (Julien 2015) and if social isolation results, this can impact physical activity, health and wellbeing (Brummett et al. 2001; Reed et al. 2011, Santos et al. 2015).

Social support emerges from a sense of community that is developed through four elements (Table 1, McMillan and Chavis 1986). While this framework pre-dates contemporary online communities, these elements have been found to form a 'virtual sense of community'. For example, Blanchard and Markus (2004) found all but a sense of influence were present in an online newsgroup for training 
athletes, while in a German online community for the elderly, all four elements were experienced (Abfalter et al. 2012).

Table 1. Dimensions of sense of community (Source: McMillan and Chavis 1986)

Dimension

Explanation

Membership

Influence

Integration and fulfilment of

needs

Emotional Connection
Feeling of belonging and sharing a sense of relatedness

Sense of mattering and making a difference

Sense that needs will be met by the resources available in the group

Belief that members share similar experiences, history, places and time together

Many studies have found positive outcomes of participation in online communities which offer opportunities for social support (Oh et al. 2014) that may otherwise be unavailable, as online communities and support groups are often used when physical social support is perceived as low (Turner et al. 2001). Despite these positive claims, Oh et al. (2014) found that online communities can produce mixed emotions, suggesting that it should not be assumed that all supportive online interactions are successful. Frison and Eggermont's (2015) study of adolescent's support seeking on Facebook found a positive outcome only when the participants experienced support that helped reinforce their personal perceptions and feelings. Users must perceive support is available for a particular issue to avoid negative outcomes, therefore, online communities may only be supportive when tailored for a specific audience. Other research suggests it is how the user chooses to connect with others online that determines a positive outcome. Passive browsing can result in upward social comparison and feelings of envy (Lin and Utz 2015) and Vogel and Rose (2016) found that focusing on other's unrealistic online self-presentation is likely to result in negative emotions.

The success of an online community is also dependent upon behaviours that benefit the group (Chiu et al. 2015) and members sharing information (Lin et al. 2015). However, research has shown that only a small percentage of online community members actively contribute by posting messages and sharing information (Nonnecke \& Preece 2000; Hung et al. 2015). The majority are 'lurkers', defined by Preece et al. (2004, pp 202) as "someone who has never posted in the community to which he/she belongs". Lurking behaviour has been widely researched due to lack of participation threatening the survival of an online community (Smith \& Kollock 1999; Bishop 2007), especially in small 
communities (Amichai-Hamburger et al. 2016). However, some studies suggest that lurking is not detrimental to communities (Yeow et al. 2006) if there are enough active participants (Preece et al. 2004). Preece et al. (2004) found five main reasons for lurking, including: not needing to post; needing to understand the group; being helpful (feeling that they had nothing extra to offer); not being able to use the software correctly; and not liking the group. These lurking motives have not been examined in the context of online running communities therefore the study may shed some light into such practices.

\section{Physical Activity, Tracking Applications and Online Communities}

There is a plethora of online activity in relation to tracking applications and running online communities, yet there has been little to no research on the uses of tracking application's community functions and the wider online activities that may be used. The lack of understanding of pre-existing usage patterns and uses of these online areas presents a gap in the current research and knowledge.

Whilst there is much to learn from the everyday use and application of such tools and online activity, studies to date remain inconclusive. For instance, a recent study found that adding a wearable device to standard interventions did not increase weight loss (Jakicic et al. 2016), and another found the addition of an online community via Facebook did not improve physical activity or the sense of community in participants (Cavallo et al. 2012). Conversely, other studies have found the use of an online health community had a positive correlation with increased exercise (Ba and Wang 2013) and Hwang et al.'s (2010) study of a large online weight loss community found that the social support received helped users cope with being overweight. The varying results from this field suggest that success is dependent upon the community of users and the support practices adopted aligned with wider research in online communities (e.g. Chiu et al. 2015; Lin et al. 2015). Supporting this, Rooksby et al. (2014) conducted qualitative interviews with a number of tracking application users, ranging from apps that track running, to sleep patterns and cafes visited. They found five styles of personal tracking, including: directive tracking (e.g. working towards a marathon or other goal); documentary tracking; diagnostic tracking; collecting rewards; and fetishized tracking (pure interest in data and technology). The complex reasons why individuals use and engage with tracking technology show that not all applications and their subsequent communities are suited to every need.

Sharing practices in online communities are also contentious with Rooksby et al. (2014) finding that although the option to 'share' data was available, no participants chose to do so. Participants reported negative feelings surrounding those who do regularly post to social media about their physical activity (Rooksby et al. 2014) and a need to manage impressions of self online (DiMicco and Millen 2007; Newman et al. 2011) hindering sharing activity. Behrendt (2016) suggests that the feelings of being 
tracked and issues of privacy were concerns of users, indicating sharing options within tracking technology may not be a key reason for engagement. Stragier et al. (2015) found that extrinsic motivators are not why individuals post about their physical activity to social media. Social outcomes including feedback, support from peers and connecting with others were not motivations for sharing this information and connecting with the broad community on social media. Users are more likely to anonymously compare their performances in leader boards and statistics (Rooksby et al. 2014; Behrendt 2016). This behaviour could be viewed as a form of 'lurking', where users do not actively contribute to a community, yet still participate silently by reading posts (Nonnecke and Preece 2000). This was particularly common with running and cycling applications. A recent study by Zhang et al. (2016) found social comparison more effective at increasing physical activity than social support in an online community.

Another explanation for the lack of contribution to communities could be the need for family and friend support, rather than strangers. Rooksby et al. found that tracking was a "co-present activity [...] often done among families, friends and co-workers" (2014 p. 1170). This suggests that rather than building an online community, tracking technologies function within an individual's physical community. In an early study using mobile phones as a health promotion tool, it was found that sharing the activity information amongst friends was motivational (Maitland et al. 2006). Therefore online communities may best motivate individuals if they bring together established physical communities.

Strong-tie relationships, such as with family and close friends (Granovetter 1973), within personal, physical communities have been shown to be important when looking at the success of social interventions to encourage physical activity. For example, a number of studies found spousal support and co-participation increase exercise participation (Raglin 2001). Research therefore suggests that programmes that incorporate family members and the environment within the neighbourhood are the most successful for encouraging physical activity. Dispersed online communities might not offer these benefits, however, those who use online communities to connect with their physical communities experience more neighbourly support than those who do not (Hampton et al. 2011). Vogel and Rose (2016) suggest that online community users should focus on connecting with friends and family rather than focusing on non-close contacts.

In essence existing research on tracking technologies and online communities is predominately quantitative, medical based studies designed to test their use as an intervention for weight loss, providing mixed results. However, there is a dearth of research into user's day-to-day engagement patterns and the related role of social support for everyday health and fitness in online 'running' space. This research therefore adopts a qualitative approach in achieving its aim and is detailed further next. 


\section{Methodology}

The research adopted an exploratory approach (Robson 1993) where by qualitative interviews were undertaken with nine UK long distance runners to gain insight into users' online activity in terms of their engagement with tracking technologies and online communities. This allowed the differing perspectives of participants and their experiences to be explored (Atieno 2009) and provided the flexibility that was essential to developing an understanding of the personal experiences of running and these technologies. The research aimed to reflect the personal experiences at the time of data collection. The semi-structured interviews were based around pre-defined and planned questions but allowed deviation (Robson 1993). This encouraged participants to focus on topics that they felt were important (Rubin and Rubin 2005), and to discuss aspects of community, running and technology that were not part of the interview guide at all (Bryman 2015). A mixture of Kvale's (1996) nine types of questions were used.

Participants were selected who had been running or jogging for at least six months and had been active online in relation to running. This ensured participants had a level of online engagement to their running habit, as new runners may not have fully engaged with, or understood, some of the online tools/communities available. Therefore, the sample was purposely selected to inform and create understanding around the research questions (Creswell 2013) related to the participant's experience of tracking technologies and online communities as part of their wider online activity in running. Initially, two participants were hand-picked based on their known experience of running. Snowball sampling (Bryman 2015) was then used, with participants introducing other relevant runners that were interested in participating. After six interviews, snowballing sampling was ended to reduce bias, as participants were introducing those with similar characteristics to themselves (Bryman 2015). The data was considered, and it was found that theoretical sampling was required to ensure the data would allow a thorough exploration into the topic (Bryman 2015). Exploration into the experiences of those who belonged to physical running groups, and those who were less serious runners was required to explore a diversity of runners' experiences. In order to achieve this, local athletic clubs and running groups were targeted to complete the sample (Table 2). Whilst there are few rules and much debate about ideal sample size in qualitative research, the final number was determined by the aim of the study, the data required to saturate categories, and what was achievable in terms of resources (Patton 2002). The final sample comprised of participants aged 20-30. This reflects an age group who are actively engaged with technology to track their fitness Statistica 2018) and therefore likely to meet the sampling criteria of using technology in relation to their running. According to the Sport England (2010) market segmentation, this age group are the most active participants in athletics (which incorporates running). 
Table 2. Characteristics of participants

\begin{tabular}{|c|c|c|c|c|c|c|}
\hline Pseudonym & Gender & Age & Location & $\begin{array}{l}\text { Running } \\
\text { Club }\end{array}$ & $\begin{array}{l}\text { Years } \\
\text { Running }\end{array}$ & Experience \\
\hline Ross & M & 30 & Brighton & $\mathrm{N}$ & 2 & Training for $1 / 2$ marathon \\
\hline Ben & M & 20 's & Swindon & $\mathrm{N}$ & 5 & $\begin{array}{l}4 \times \text { Marathons and several } \\
1 / 2 \text { marathons }\end{array}$ \\
\hline Miles & M & $20 ’ \mathrm{~s}$ & Dorset & $\mathrm{N}$ & 2 & $1 \times 1 / 2$ marathon \\
\hline Angela & $\mathrm{F}$ & 22 & Dorset & $\mathrm{Y}$ & 4 & $\begin{array}{l}\text { Several ultra-marathons, } 1 \\
\text { Marathon and several } \\
1 / 2 \text { marathons }\end{array}$ \\
\hline Elizabeth & $\mathrm{F}$ & 23 & Dorset & $\mathrm{Y}$ & 7 & $\begin{array}{l}1 \text { Marathon and several 1/2 } \\
\text { marathons }\end{array}$ \\
\hline Eric & M & 19 & Dorset & $\mathrm{Y}$ & 7 & $\begin{array}{l}\text { Competes nationally in } 1500 \mathrm{~m} \\
1 \times 1 / 2 \text { marathon }\end{array}$ \\
\hline Ryan & M & 29 & Dorset & $\mathrm{Y}$ & 3 & $\begin{array}{l}5 \times \text { Marathons } \\
5 \times \text { half marathons }\end{array}$ \\
\hline Molly & $\mathrm{F}$ & 29 & Yorkshire & $\mathrm{N}$ & 0.5 & $3 \mathrm{x} \mathrm{km} \mathrm{race}$ \\
\hline Sally & $\mathrm{F}$ & 19 & Dorset & $\mathrm{Y}$ & 2 & $2 \mathrm{x}$ marathons \\
\hline
\end{tabular}


Interviews were conducted either face-to-face, or via Skype video calls, and lasted between 30 and 40 minutes. Skype interviews offered flexibility and convenience (Bryman 2015) allowing the inclusion of participants from a number of locations in England. After each semi-structured interview, notes were made on the key points each participant had suggested and overall experience of the data collection process. This allowed another source of data for analysis, and also highlighted any issues with questions so the guide could be altered for the next interview.

Creswell's 'Data Analysis Spiral' (2013) was used to guide the analysis process. The emerging concepts and ideas were noted, and the process of data cleansing was carried out to ensure accurate transcription (Saunders et al. 2009). Describing, classifying and interpreting the data into codes and categories was then undertaken. It was essential to develop tentative themes (Creswell 2013) that began to question and explore engagement patterns and the role of social support within online communities and tracking technology. Interpretation of the data was carried out (Angen 2000) to form a larger exploration of the aim by linking the themes to existing literature, as well as to insights drawn from within the data itself (Creswell 2013). Finally, the data was represented visually via an illustration, (see Figure 1), to clearly present findings and relationships between the concepts that emerged. Member validation with select participants ensured the experiences of participants' online activity were appropriately interpreted. Three sources of data were used during the analysis, including the transcriptions, research notes and the literature which lead to greater evidence for the emerging themes, and therefore credibility through triangulation (Guba and Lincoln 1994; Creswell 2013).

\section{Findings and Discussion}

The participants in this study exhibited diverse running experiences and preferences for running alone or in groups. This is indicative of running being a personal sport, with some personalities and running styles leading to engagement on a social level, and others preferring to keep running as a solitary exercise. All participants used social media and there was some commonality in use of tracking technology though sharing practices with this data varied. The data suggested that the range of online activity could be grouped according to use of: social networking sites; running club online communities; and tracking applications. The following discussion develops understanding of the prominent use practices and provision of social support that emerged as a result in these areas from the data.

\section{Social Networking Sites}

Mainstream social networking sites, including Facebook, Instagram and Twitter, were frequently used by participants. Different use patterns were apparent between these sites, however the differences between these platforms is not a focus of this study. Instead analysis maps runner's engagement with social networking sites as a whole to explore the view that these can provide social support. Every 
participant engaged with social networking sites by posting images related to their runs. Some participants posted images of themselves running and medals won, whilst others never overtly posted about their running, instead sharing pictures of sunsets taken during the run or of their new trainers. The comments received in response to posts provided "a bit of motivation" (Elizabeth) for participants, showing that social networking site engagement can enable the exchange of social support (Hajli et al. 2013, Oh et al. 2014) for runners. This motivational aspect was positive for all participants but managed by participants with care and as a platform for social support, social networking sites had limitations. Further analysis suggested that support seeking is not the primary purpose of social networking sites for runners. In most cases images are shared with caution to display identity. For example, Ben would post pictures achievement pictures after a race "I would probably put a picture of my medal on Instagram or Twitter" whilst Molly posts images that are "representing a change in my lifestyle". Thus participants shared photos that construct their identity as a runner (Van Dijck 2008), supporting the growing body of literature that finds identity formation a primary use of social networking sites (Eftekhar et al. 2014; Van Dijck 2013, Zhao et al. 2008).

While posting images to form identity is an important use of social networking sites for runners, participants also expressed negative views about runners who regularly posted:

"I think Facebook and Instagram annoys me in general... when people feel the need to constantly post things about their life. So I think the same with fitness and running." (Molly)

Throughout her interview Molly exhibited complex and inconsistent feelings and engagement patterns with social networking sites. For example:

"I post pictures to Instagram... I never say how far I've run or what I have done but... at the end of my run if it's a nice view at sunset I might take a picture... things like that. But I don't want to be posting about how far I've run or what I have done. Cause I see that as quite personal to me, I want to track my progress. I don't want other people to be saying stuff about it if you get what I mean."

This illustrates the ambiguity around its use as a supportive community for runners and Molly's quote reflects her awareness of impression management (DiMicco \& Millen 2007). In this respect, most participants regarded posting on social networking sties with some apprehension, making sure to point out they only occasionally post material about running, and do not post "every time I go out for a run because that, I think, is just boring people" (Ryan). Some participants never posted to social networking sites directly about running, stating: "I don't want to be seen as kind of showing off" (Eric). Participants carefully select when to actively engage with social networking sites to avoid overloading their audience : 
"It was only when I was doing a big event, like a marathon or half marathon" (Elizabeth)

"I never post anything at the beginning of the training program [...] But then when it gets intense and you know you get the really good times then I do share it quite often" (Angela)

Participants used social networking sites to portray their ideal self (Goffman 1990) and display positive aspects of their identity as runners (Qiu et al. 2012). This supports Newman et al.’s (2011) suggestion that, in relation to health and fitness, social networking sites act as the 'front stage' (Goffman 1990), a place for runners to communicate their achievements and identities. The findings show that supportive interactions rarely extend beyond likes and 'well done' comments on social networking sites and more depth support, such as giving advice is limited. Participants were also cautious about exposing their limitations with some participants deleting data that might otherwise be shared. For example, Angela describes "if it is a result that I really don't want people to see... then I delete it... but if I delete it, then I can't look back at it either".

On the other hand, participants found motivation from passively browsing social networking sites with little active engagement. This was achieved by following established running sites and browsing other runner's posts, for example:

“Runner's World has an Instagram page and they always post really motivational stuff. Like 'oh you need to get out of bed and do it"' (Angela)

"Someone posted a before and after photo the other day of their marathon times and it's just, it really motivates you to do the same. Especially if their starting time was like the same as yours. So you think like, you can do the same." (Sally)

This suggests passive social networking site use does not always have a negative detrimental effect as other studies have uncovered (e.g. Sagioglou and Greitemyer 2014; Lin and Utz 2015; Vogel and Rose 2016) and is congruent with Frison and Eggermont's (2015) finding that social networking sites are positive when matched to a specific need. Furthermore, Sally's experience suggests that social comparison via social networking sites can be motivational, in particular comparison with a runner of similar ability. This contributes to the conflicting body of literature on social comparison and social networking site use, with both upward and downward comparisons creating negative and positive emotions (Suls et al. 2002; Vogel and Rose 2016). However, the data suggests that for runners, comparison with similar others provides feelings of inspiration, or hope (Taylor and Lobel 1989; Wheeler and Miyake 1992), that acts as motivation to achieve running goals. 


\section{Tracking Application Use}

Separating out the more generic online activity on social networking sites in the section previous, every participant made reference to using a tracking application, indicating the popularity of their use amongst runners. For many, the use of a tracking application was simply determined by which synched with their wearable device, for example Molly and her Fitbit: "cause I got a FitBit, I track my FitBit through the app. " Participants often disengaged with a tracking application in favour of another after switching wearables e.g. FitBit to Garminn, suggesting the compatibility with other running technology is a major factor that determines engagement.

Most tracking applications mentioned by participants included an online community function, enabling users to follow and be followed by other runners, as well as view and comment on other's running activities. Participants reflected on how these applications had become "basically like a Facebook" (Elizabeth) for some runners:

"I guess you can call Strava (a type of tracking application) social networking, cause I use it every day [...] I use it quite like, socially, so I do follow about 50 odd people and I'm followed by 50 odd people...." (Ben)

However, only four participants (Ben, Eric, Sally and Ryan) frequently engaged with the community functions of tracking applications. These participants were experienced runners, and three were members of running clubs. The majority of participants did not regularly engage socially with the community function of tracking applications. Elizabeth says simply; "I just forget to go on". Though requiring further investigation, the heavily involved runners, such as Sally Ben, Eric and Ryan, utilised the community function of tracking applications far more than the casual runners in the sample. On the other hand, the more casual runners had fewer followers who were largely those engaged in co-present running activities. This suggests not all runners will benefit from the social tools provided by tracking applications, therefore not optimising its social support 'capacity'.

Analysis found that tracking application data was frequently shared with a runner's off-line physical community where runners share data with friends, family and running partners in such settings. For example, Angela describes the sharing practices of her running group to their Facebook group:

"post run we post, pictures that let say I took or we took and then, we share how good it was and then maybe a screen shot of how well we've done as well" 
Sharing tracking application data is therefore a 'co-present activity' for participants (Rooksby et al. 2014). Tracking applications provide an in-depth tool for social comparison, providing a way to share data with friends and family, in turn creating support and motivation (Maitland et al. 2006). This is significant as social support from strong ties (Granovetter 1973) is consistently found to be important for encouraging physical activity (e.g. Mama et al. 2015; Ransdell et al. 2003). In tracking application online communities, the presence of strong ties was found to impact the engagement of participants. Eric's close knit community on his tracking application meant he would "filter out the bad ones, filter out the things I know people will look at with a bit of concern," when deciding which runs to post. Elizabeth describes how having a family member in her tracking application community affects her use: "I think if I upload it to Strava, I think my Dad can see how bad it has been". This perceived negative impact on engagement suggests that tracking applications for some have a down side when used 'co-presently' with strong ties, in this case directly with a family member.

Although the presence of strong ties had some detrimental impact on active engagement it was largely beneficial. Conversely, most participants found strangers who followed them on tracking applications "a bit strange" (Ben). This suggests that tracking application communities work best where participants have the equivalent in physical connections. For example, Eric, one of the most engaged with the community functions stated:

"Everyone I have on Strava I know, and if someone random followed me I would probably just ... reject it." (Eric)

This finding is in line with existing research suggesting young people rarely interact with strangers online to avoid risk (Wang and Edwards 2016). It appears tracking application communities do not create supportive networks of strangers, however, they are an important tool for runners to connect within physical off-line community equivalents.

“There's quite a few people at work who I don't really talk to that much, but because I've connected with them on Strava, it's quite good to have something in common. So you can like 'like' their run or comment on it." (Ben)

Here Ben uses his tracking application to aid in the development of 'loose' tie relationships with other runners. Tracking applications create an online environment purely for runners allowing networks to develop that can provide specific support. This is a key benefit of tracking applications, as online communities that match user's needs can provide a platform for social support (Frison and Eggermont 2015). 
An important function of tracking applications was capturing data with most recording data on every run:

"I like to see the mileage and what I do per week and how fast I am, rather than just going out and running for the sake of it. It is nice to be able to quantify how much I have run." (Elizabeth)

Tracking applications act like personal informatics systems, enabling participants to gain knowledge about their running performances (Li et al. 2010), and quantify their activities (Shin and Biocca 2017). Collation of personal data is a key reason for engagement. The data collected allowed comparisons with the user's previous performances, and with other runners, in turn increasing motivation through documenting improvement:

"I use Garmin for tracking progress and comparing fitness levels [...] It tracks your cadence, tracks your speed. It's ideal for seeing your improvements basically." (Ryan)

The variety of data gained from their tracking applications allows in depth analysis of performance which is motivational (Asimakopoulos et al. 2017). This was extended by the interplay with the community aspect:

"You could compare how you were running, how often you were running. You could compare who was burning so many calories and who is doing a good distance." (Miles)

"You can see how much you've done compared with others. [...] you know if you're both training for something and you're a bit ahead of them [...] and if you're not ahead of them it makes you work harder." (Sally)

This suggests motivation for running is not only increased by the data collected as Asimakopoulos et al. (2017) suggest, but by comparing this to other runner's achievements within the community. It also reinforces the membership element that McMillan and Chavis (1986) identify. Though not a tracking technology as such, Sally referred to the 'Power of 10' website which captures results data from UK athletics events. As with the negative issues of sharing poor runs, Sally indicates Power of 10 led to social comparison and could be detrimental.

Participants held an emotional connection to their collected data and stored runs. Whilst participants enjoyed looking over their past runs to see improvements "and monitor change over time" (Miles), for some, recording runs went further than this. Many participants recorded every run without fail, 
expressing that it "feels wrong if I go out without it" (Sally) and feelings of irritation and disappointment if the tracking application did not work correctly:

"I feel like, disappointed and like I would have to go and do that run again if it's not recorded it properly" (Molly)

These participants are dependent on tracking applications to document they completed their runs, making them essential tools: "I must admit the app is probably the one thing that I couldn't do without" (Ross). Participants were not just documenting their runs for interest or to discover routines as Rooksby et al. (2014) suggest. Undocumented runs become "worthless" (Ben), demonstrating the strong emotional connection they create:

"If there wasn't somewhere to post your activity, you wouldn't get as much joy out of it, because you'd forget about it. If you post it, it's always there-it's got like a digital stamp. So you can always recall it in the future." (Ben)

In a sense, the tracking applications allow a platform for another of McMillan and Chavis (1986) sense of community dimensions, in that 'integration and fulfilment of needs' by a runner is facilitated by the 'digital stamp'. Comparatively tracking applications offer a way to log, remember and re-live the experience (Dobbins et al. 2013). Runners use tracking applications to create a keepsake and 'mediated memory' of their run (Lingel and Naaman 2011). This demonstrates the emotional connection humans can have with tracking applications (Rooksby et al. 2014), suggesting consistent engagement over a long period of time is possible for some runners, an important finding in relation to their overall online activity and a potential vehicle to building online communities (Blanchard and Markus 2004, Abfalter et al. 2012).

\section{Running Online Communities}

Of the nine runners in the study sample, five were members of running and athletics clubs, and one (Elizabeth) was involved in organising club sessions. Every member described regularly using their club's online community, as they offer an easy way to share information and aid in the planning and organisation of sessions:

"They kind of put up what we are doing in training. Erm... any kind of news about the newest technology, shoes, if they are selling anything. " (Eric) 
Participants were able to access useful information about running and check "what's going on and if there is a change of plan" (Ryan). The technological features of platforms like Facebook's 'page' function aide organisers in providing a dedicated online community space, and share in communication and session planning:

"We could check who was coming to the sessions [...] you send out messages and you can see who has read it, so you know kind of who will turn up..." (Elizabeth)

Elizabeth used Facebook's 'seen message' feature (Facebook 2017) to gain information about participation. This saved time and resources as each member did not have to be contacted individually. Club communities enable communication and information sharing in 'cyberplace' (Wellman 2001) with the technological features benefitting members and organisers, and facilitating information sharing that may not have been possible during physical meetings alone.

The engagement of members in running club communities led to a supportive community involving encouragement and shared experiences:

"With Facebook you're all like encouraging each other and sharing what you've done [...] we are all posting things about the competitions we'd all been to." (Sally)

An emotional connection is created by sharing experiences online, developing the sense of community within the group (McMillan and Chavis 1986) to create an encouraging and socially supportive club. This is congruent with Hampton et al.'s (2011) suggestion that physical communities who connect online experience high levels of support. However, club communities must have high levels of engagement from members to become supportive (Chiu et al. 2015) and runners had to build confidence as a runner in order to post or comment. Elizabeth acknowledges how lack of engagement affected the success of her community:

"It is still them replying [that is the issue]. We sent out something yesterday and we only got like 3 responses. [...] So it is good and it is bad I think, in different ways. It just depends how people use it." (Elizabeth)

This shows that while club communities have the potential to create supportive communities, they are dependent on the members' interaction to be successful (Smith and Kollock 1999; Chiu et al. 2015; Lin et al. 2015). Elizabeth explained how engagement was affected by length of membership and a need for members to bond before active participation could occur: 
"[When] we first started the Athletics group... I didn't really know anyone and I didn't feel like I could post anything" (Elizabeth)

The 'new' status of the community meant ties had not yet developed, or were weak, reducing active participation. Elizabeth acknowledged her own insecurities as a new and younger member of the group which inhibited her contribution at first. This is an issue for club communities, suggesting new groups and members may not benefit from the social capital the community can bring. Lack of ties strength means members do not engage and interact, and therefore cannot access some of the resources of the community (Coleman 1988), such as lift sharing (Lovejoy and Handy 2011), that would enable physical activity. This highlights the importance of members actively posting within club communities regardless of whether they 'know anyone', as weak-ties are valuable for navigating the logistics of running clubs.

\section{Insert FIGURE 1}

\section{Conclusion}

This study has critically analysed runners' online activity engagement in relation to: social networking sites, tracking applications and online communities in order to explore the presence of social support for runners. Analysis has identified distinct use practices associated in each of these areas (see Figure $1)$.

The diverse needs and technology uses of the runners participating in this exploratory study suggest that social support from online activity is varied. Participants were cautious when contributing actively to most online community areas. In many instances participants preferred to lurk silently, gathering information and motivation. Active and supportive contribution to running online communities was dependent on place-based, strong-tie connections with other members of the community, and while some participants did engage with tracking applications in a social manner, analysis of this data revealed a predominant use for data collection. These findings question the extent to which online communities bring together individuals to share support. Instead this research suggests that online communities are complex and individual, with users engaging with them for a host of differing reasons.

The findings gained from this study have a number of important implications for the development of online communities in practical contexts and for tracking application technology developers. For example heavily involved, experienced runners appeared to be more engaged with online 
communities. The members of the community also had an impact on engagement. There is a need for awareness of the complex engagement practices of runners with online communities. Factors such as running experience and style influence engagement patterns, showing the need for online communities to meet the needs of diverse users and experience levels in order to provide support.

Online communities in the running context may not be as beneficial for social support in every instance, as previously found in other studies (Blanchard and Markus 2004, Abfalter et al. 2012). The evidence from this exploratory study indicates that online communities should not expect to connect strangers spread further afield when seeking to develop a supportive fitness community. Therefore online activities that focus less on spatially diverse networks of strangers, but on improving close communities built upon strong ties (Granovetter 1973) could have more positive outcomes for their participants.

Tools that facilitate physical connections through online communities are important as the social, "copresent' (Rooksby et al. 2014) dimension of tracking applications could be further developed. So too can the reinforcement of 'integration and fulfilment of needs' (MacMillan and Chavis 1986) as a sense of community be enhanced. High levels of dependence and engagement with tracking technologies suggest the market will continue to grow for these applications. The emotional attachment to recording runs could be developed through evolving technology to better meet this need. To further explore the causes of disengagement with tracking applications and online communities, future research should source participants who completely disengage, or never engaged at all in online communities or applications. This would develop understanding around the topic and also reach groups of the population who are less likely to become involved with online tools that support fitness.

The specific sample of runners means findings cannot be transferred to the wider population, limiting the generalisability of the findings (Angen 2000, Guba and Lincoln 1994). However, they provide an insight that warrants further research into the presence and role of social support in areas of online activity. Positive aspects of engagement practices have been identified such as the emotional importance of data, however, social support is less extensive than studies in health have suggested. The research shows that tracking applications, online communities and social networking site use has a steady trend. This is reflected in the wider population, with a multitude of online activity platforms accessible and available in day to day life. The findings show that follow on research would benefit from a deeper understanding of online activity engagement behaviours within online communities, social networking sites and related tracking applications. In so doing, a deeper understanding into the potential areas that benefit from improving on the social support functionality of online activity is brought into the fore. 


\section{References}

Abfalter, D., Zaglia, M. and Mueller, J., 2012. Sense of virtual community: A follow up on its measurement. Computers. Human Behavior [online], 28 (2), 400-404.

Amichai-Hamburger, Y., Gazit, T., Bar-Ilan, J., Perez, O., Aharony, N., Bronstein, J. and Sarah Dyne, T., 2016. Psychological factors behind the lack of participation in online discussions. Computers in Human Behavior [online], 55, 268-277.

Angen, M. J., 2000. Evaluating interpretative inquiry: Reviewing the validity debate and opening dialogue. Qualitative Health Research. 10, 378-395.

Asimakopoulos, S., Asimakopoulos, G. and Spillers, F., 2017. Motivation and User Engagement in Fitness Tracking: Heuristics for Mobile Healthcare Wearables. Informatics [online]. 4(1), 1-16.

Atieno, O.P., 2009. An Analysis of the Strengths and Limitations of Qualitative and Quantitative Research Paradigms. Problems of Education in the 21st Century. 13, 13-18.

Ba, S. and Wang, Lei., 2013. Digital health communities: The effect of their motivation mechanisms. Decision Support Systems [online], 55, 941-947.

Bauman, A., Reis, R., Sallis, J., Wells, J., Loos, R. and Martin, B., 2012. Correlates of physical activity: why are some people physically active and others not?. The Lancet [online], 380(9838), 258271.

Behrendt, F., 2016. Why cycling matters for Smart Cities. Internet of Bicycles for Intelligent Transport. Journal of Transport Geography [online], 56, 157-164.

Bishop, J., 2007. Increasing participation in online communities: A framework for human-computer interaction. Computers in Human Behavior [online], 23(4), 1881-1893.

Blanchard, A. and Markus, M., 2004. The experienced "sense" of a virtual community. ACM SIGMIS Database[online], 35(1), 64.

Brummett, B., Barefoot, J., Siegler, I., Clapp-Channing, N., Lytle, B., Bosworth, H., Williams, R. \& Daniel, M. 2001. Characteristics of Socially Isolated Patients With Coronary Artery Disease Who Are Elevated Risk of Mortality. Psychosomatic Medicine. 63 (2) pp 267-272.

Bryman, A., 2015. Social Research Methods. $5^{\text {th }}$ ed. Oxford: Oxford University Press.

Cassel, J., 1976. The contribution of the social environment to host resistance. Am J Epidemiol [online], 104, 107-123.

Cavallo, D. N., tate. D. F., Ries, A. V., Brown, J. D., DeVellis, R. F and Ammerman, A.S., 2012. A social media-based physical activity intervention: a randomized controlled trial. American Journal of Preventative Medicine [online]. 43(5) 527-532.

Chiu, C., Huang, H., Cheng, H. and Sun, P., 2015. Understanding online community citizenship behaviors through social support and social identity. International Journal of Information Management [online], 35(4), 504-519.

Clough, P., Shepherd, J., \& R. Maughan. 1989. Motives for Participation in Recreational Running. Journal of Leisure Research. 21 (4) pp 297-310.

Cobb, S., 1976. Social Support as a Moderator of Life Stress. Psychosomatic Medicine [online], 38(5), 300-314. 
Coleman, J. S., 1988. Social Capital in the Creation of Human Capital. American Journal of Sociology [online], 94. S95-S120.

Comstock, J., 2013. 7 fitness apps with 16 million or more downloads. Mobihealthnews [online], $26^{\text {th }}$ August 2013. Available from: http://www.mobihealthnews.com/24958/7-fitness-apps-with-16million-or-more-downloads/page/0/6 [4/5/17]

Creswell, J. W., 2013. Qualitative Inquiry and Research Design: Choosing Among Five Approaches. $3^{\text {rd }}$ ed. London: Sage.

Deloitte, 2015. Connected Health. How digital technology is transforming health and social care [online].London: Deloitte.

DiMicco, J. M. and Millen, D. R., 2007. Identity management: multiple presentations of self in facebook. Proc. GROUP [online], 383-386.

Dobbins, C., Merabti, M., Fergus, P. and Llewellyn-Jones, D., 2013. Creating Human Digital Memories for a Richer Recall of Life Experiences [online]. In: 2013 10th IEEE International Conference on Networking, Sensing and Control (ICNSC), Evry France, April 2013. IEEExplore. 246-251.

Eftekhar, A., Fullwood, C. and Morris, N., 2014. Capturing personality from Facebook photos and photo-related activities: how much exposure do you need? Computers in Human Behavior [online]. $37,162-170$.

Facebook, 2017. How do I know if a friend has seen a message I sent on Facebook? [online]. Facebook. Available from: https://www.facebook.com/help/316575021742112 [24/4/17].

Frison, E. and Eggermont, S., 2015. The impact of daily stress on adolescents' depressed mood: The role of social support seeking through Facebook. Computers in Human Behavior [online], 44(2005), 315-325.

Goffman, E., 1990. The Presentation of Self in Everyday Life [online]. London: Penguin Books.

Goodsell, T. \& Harris, B., 2011. Family Life and Marathon Running: Constraint, Cooperation, and Gender in a Leisure Activity. Journal of Leisure Research. 43 (1) pp 80-119.

Granovetter, M. S., 1973. The Strength of Weak Ties. American Journal of Sociology [online], 78(6), $1360-1380$.

Guba, E. G. and Lincoln, Y. S., 1994. Competing paradigms in Qualitative Research. In N K. Denzin and Y. S Lincoln (eds) Handbook of Qualitative Research. Thousand Oaks, CA: Sage.

Hajli, M. N., Sims, J., Featherman, M. and E.D. Love, P. E. D., 2013. Credibility of information in online communities. Journal of Strategic Marketing [online]. 23 (3), 238-253.

Hampton N. K., Goulet L. S., Rainie. L. and Purcell. K., 2011. Social Networking Sites and our Lives [online]. Washington DC: Pew Internet Project.

Hung, S., Lai, H. and Chou, Y., 2015. Knowledge-sharing intention in professional virtual communities: A comparison between posters and lurkers. Journal of the Association for Information Science and Technology [online], 66(12), 2494-2510. 
Hwang, O. H., Ottenbacher, A. J., Green, A. P., Cannon-Diehl, M. R., Richardson, O., Bernstam, E. V. and Thomas, E. J., 2010. Social support in an Internet weight loss community. International Journal of Medical Informatics[online], 79 (1), 5-13.

Jakicic, J., Davis, K., Rogers, R., King, W., Marcus, M., Helsel, D., Rickman, A., Wahed, A. and Belle, S., 2016. Effect of Wearable Technology Combined With a Lifestyle Intervention on Longterm Weight Loss: The IDEA Randomized Clinical Trial. JAMA [online], 316(11), 1161.

Julien, C., 2015. Bourdieu, Social Capital and Online Interaction. Sociology, 49 (2) pp 356-373.

Krebs, P. and Duncan, D. T., 2015. Health App Use Among US Mobile Phone Owners: A National Survey. Journal of Medical Internet Research [online]. 3 (4), 1-12.

Kvale, S., 1996. InterViews: An Introduction to Qualitative Research Interviewing. CA: Sage.

Li, I., Dey, A.K., Forlizzi, J., 2010. A stage-based model of personal informatics systems [online]. In: CHI' 10: Proceedings of the SIGCHI Conference on Human Factors in Computing Systems. Atlanta, Georgia USA 10-15 April 2010. New York: ACM. 557-566.

Lin, R. and Utz, S., 2015. The emotional responses of browsing Facebook: Happiness, envy, and the role of tie strength. Computers in Human Behavior [online], 52, 29 -38.

Lin, T., Hsu, J., Cheng, H. and Chiu, C., 2015. Exploring the relationship between receiving and offering online social support: A dual social support model. Information \& Management [online], 52(3), 371-383.

Lingel, J. and Naaman, M., 2011. You should have been there, man: Live music, DIY content and online communities. New Media and Society [online]. 14 (2), 332-349.

Lovejoy, J. \& Handy, S., 2011. Social networks as a source of private-vehicle transportation: The practice of getting rides and borrowing vehicles among Mexican immigrants in California.

Transportation Research Part A, 45, 248-257.

Maitland, J., Sherwood, S., Barkhuus, L., Anderson, I., Hall, M., Brown, B., Chalmers, M., \& Muller, H. 2006. Increasing the Awareness of Daily Activity Levels with Pervasive Computing. Pervasive Health Conference and Workshops, Nov $29^{\text {th }}-$ Dec $1^{\text {st }}, 2006$. Innsbruck, Austria. IEEE

Mama, S. K., McCurdy, S. A, Evans, A. E., Thompson, D. I., Diamond, P. M. and Lee, R. E., 2015. Using Community Insight to Understand Physical Activity Adoption in Overweight and Obese African American and Hispanic Women: A Qualitative Study. Health, Education and Behaviour [online], 42 (3), 321-328.

McMillan, D. and Chavis, D., 1986. Sense of community: A definition and theory. Journal of Community Psychology [online], 14(1), 6-23.

Mintel, 2016. Wearable Technology, UK-December 2016 [online]. London: Mintel.

Mintel, 2017. Digital Trends Spring, UK, April 2017 [online]. London: Mintel.

Newman, M. W., Lauterbach. D., Munson, S. A., Resnick. P. and Morris, M. E., 2011. It's not that I don't have problems, I'm just not putting them on facebook: challenges and opportunities in using online social networks for health. Proceedings of the ACM 2001 conference on Computer supported cooperative work [online]. 341-350. 
Nonnecke, B. and Preece, J., 2000. Lurker demographics: Counting the silent. Proceedings of the SIGCHI on Human Factors in Computing Systems [online], 2(1), 73-80.

Oh, H. J., Ozkaya, E. and Larose, R., 2014. How does online social networking enhance life satisfaction? The relationships among online supportive interaction, affect, perceived social support, sense of community, and life satisfaction. Computers in Human Behaviour [online]. 30. 69-78.

Patton, M., 2002. Qualitative Research and Evaluation Methods. $3^{\text {rd }}$ ed. London: Sage.

Preece, J., Nonnecke, B. and Andrews, D., 2004. The top five reasons for lurking: improving community experiences for everyone. Computers in Human Behaviour [online], 20, 201-223.

Public Health England, 2016. Physical inactivity: economic costs to NHS clinical commissioning groups [online]. UK: Public Health England.

Putnam, R. D., 1995. Bowling Alone: America's Declining Social Capital. Journal of Democracy [online], 6(1), 65-78.

Qiu, L., Lin, H., Leung, A. K. and Tov, W., 2012. Putting their best foot forward: emotional disclosure on Facebook. Cyberpsychology, Behavior, and Social Networking [online]. 15, 569-572.

Raglin, J., 2001. Factors in Exercise Adherence: Influence of Spouse Participation. Quest [online], 53(3), 356-361.

Ransdell, L. B., Taylor. A., Oakland, D., Schmidt, J., Moyer-Mileur. L. and Shultz, B., 2003. Daughters and Mothers Exercising Together: Effects of Home- and Community-Based Programs. Medicine and Science in Sports and Exercise [online], 35 (2), 286-295.

Reed, S., Crespo, C., Harvey, W. and Andersen, R., 2011. Social isolation and physical inactivity in older US adults: Results from the Third National Health and Nutrition Examination Survey. European Journal of Sport Science [online], 11(5), 347-353.

Robson, C., 1993. Real World Research: a resource for social scientists and practitioner-researchers. Oxford, Blackwell.

Rooksby, J., Rost, M., Morrison, A. and Chalmers, M., 2014. Personal Tracking as Lived Informatics. Proceedings of the SIGCHI Conference of Human Factors in Computing Systems [online]. 1163-1172.

Rubin, H. J. and. Rubin, I. S., 2005. Qualitative Interviewing - The Art of Hearing Data. 2nd Ed. London: Sage.

Sagioglou, C. and Greitemeyer, T., 2014. Facebook's emotional consequences: Why Facebook causes a decrease in mood and why people still use it. Computers in Human Behavior [online]. 35, 359-363.

Santos, T., Gaspar de Matos, M., Simoes, C. and Machado, M. C. 2015. Psychological Well-being and chronic condition in Portuguese Adolescents. International Journal of Adolescence and Youth. 20 (3), $334-345$.

Saunders, M., Lewis, P. and Thornhill, A., 2009. Research Methods for Business Students. $5^{\text {th }}$ ed. Harlow: Prentice Hall.

Sherwood, N. E. and Jeffery, R. W., 2000.The Behavioral Determinants of Exercise: Implications for Physical Activity Interventions. Annual Review of Nutrition [online], 20, 21-44. 
Shin, D. and Biocca, F., 2017. Health experience model of personal informatics: The case of a quantified self. Computers in Human Behavior [online]. 69, 62 -74.

Smith, M. A., and Kollock, P.,1999. Communities in cyberspace [online]. London: Routledge.

Sport England, 2010. Market Segmentation. Available from: http://segments.sportengland.org/.

Statistica, 2018. Share of people worldwide who used technology to track their fitness 2016, by age. Available from: https://www.statista.com/statistics/742448/global-fitness-tracking-and-technologyby-age/

Stragier, J., Evens, T. and Mechant, P., 2015. Broadcast yourself: An exploratory study of sharing physical activity on social networking sites. Media International Australia [online], 155, 120-129.

Suls, J., Martin, R. and Wheeler, L., 2002. Social comparison: Why, with whom, and with what effect? Current Directions in Psychological Science [online]. 11(5), 159 - 163.

Taylor, S. E. and Lobel, M., 1989. Social comparison activity under threat: Downward evaluation and upward contacts. Psychological Review [online]. 96(4), 569- 575.

Turner, J. W., Grube, J. A. and Meyers, J., 2001. Developing an optimal match within online communities: an exploration of CMC support communities and traditional support. Journal of Communication [online], 51, 231-251.

Valencell, 2016. National Wearables Survey Reveals Accuracy is Top Priority among Consumers; Lack of Continually Interesting Insights among Top Reasons for Discontinued Use [online]. New York: Valencell.

Van Dijck, J., 2008. Digital photography: Communication, identity, memory. Visual Communication [online]. 7(1), 57-76.

Van Dijck, J., 2013. 'You have one identity': performing the self on Facebook and LinkedIn. Media, Culture \& Society. 35 (2). Pp 199-215.

Vogel, E. and Rose, J., 2016. Self-reflection and interpersonal connection: Making the most of selfpresentation on social media. Translational Issues in Psychological Science [online], 2(3), 294-302.

Wang, V. and Edwards, S., 2016. Strangers are friends I haven't met yet: a positive approach to young people's use of social media. Journal of Youth Studies [online]. 19 (9), 1204-1219.

Wellman, B. and Wortley, S., 1990. Different Strokes from Different Folks: Community Ties and Social Support. American Journal of Sociology [online]. 96 (3), 558-588.

Wellman, B., 2001. Physical Place and Cyberplace: The Rise of Personalized Networking. International Journal of Urban and Regional Research [online], 25(2), 227-252.

Wellman, B., Haase, A., Witte, J. and Hampton, K., 2001. Does the Internet Increase, Decrease, or Supplement Social Capital?: Social Networks, Participation, and Community Commitment. American Behavioral Scientist [online], 45(3), 436-455.

Wheeler, L. and Miyake, K., 1992. Social comparison in everyday life. Journal of Personality And Social Psychology [online]. 62(5), 760-773.

Wilcox, K. and Stephen, A., 2013. Are Close Friends the Enemy? Online Social Networks, SelfEsteem, and Self-Control. Journal of Consumer Research [online], 40(1), .90-103. 
Yoew, A., Johnson, S., \& Faraj, S., 2006. Lurking: Legitimate or Illegitimate Peripheral Participation? ICIS Proceedings of the $27^{\text {th }}$ International Conference on Information Systems, Milwaukee, Wisconsin. December 2006. ICIS.

Zhang, J., Brackbill, D., Yang, S., Becker, J., Herbert, N. and Centola, D., 2016. Support or competition? How online social networks increase physical activity: A randomized controlled trial. Preventative Medicine Reports [online]. 4, 453-458.

Zhao, S., Grasmuck, S. and Martin, J., 2008. Identity construction on Facebook: Digital empowerment in anchored relationships. Computers in human Behaviour [online]. 24 (5), 1816-1836. 